\title{
Machiavellianism and Schadenfreude in Women's Friendships
}

The present study investigated the relationship between Machiavellianism, envy, competition, and schadenfreude in women's same-sex friendships. Women $(N=133)$ completed an online questionnaire measuring Machiavellianism, envy, competition, and three author generated vignettes measuring expressed schadenfreude in relation to a same-sex friend. Women with higher levels of Machiavellianism expressed greater feelings of pleasure in response to their same-sex friend's misfortunes in a romantic relationship and their physical appearance but not in relation to academic abilities. Envy predicted feelings of schadenfreude in academic and romantic relationships whilst competition predicted feelings of schadenfreude in all three scenarios. Future research should explore how characteristics of the target and different forms of envy may influence responses to a friend's misfortune in individuals with higher levels of Machiavellianism.

Keywords: friendships; Machiavellianism; misfortune; schadenfreude; women 


\section{Introduction}

Schadenfreude describes the experience of taking pleasure in another person's misfortune (Takahashi et al., 2009) and has received little attention in psychological literature, particularly in the context of close personal relationships. Research has started to investigate the individual differences that may predict schadenfreude, finding factors such as resentment deservingness, envy, and competition are influential in taking pleasure in someone's misfortune (Feather \& Nairn, 2005; Smith, Powell, Combs, \& Schurtz, 2009; van Dijk, Ouwerkerk, Goslinga, Nieweg, \& Gallucci, 2006). More recently, research has considered how malevolent personality factors such as the dark triad influence schadenfreude, finding that they have different relationships with feelings of schadenfreude in different contexts (James, Kavanagh, Jonason, Chonody, \& Scrutton, 2014). For instance, Psychopathy was associated with schadenfreude in the callous, competition, and failure of another scenarios whilst Machiavellianism was associated with schadenfreude in relation to competition and failure, highlighting differences between these two personalities in relation to experiencing schadenfreude. Such differences may be explained by Machiavellianism being characterized by using exploitation and manipulation for long-term goals, unlike Psychopathy which is characterized by callousness, impulsivity, and low anxiety about the consequences of their actions (Boddy, Ladyshewsky, \& Galvin, 2010; Christie \& Geis, 1970; Jones \& Paulhus, 2011).

Previous research has indeed shown that Machiavellianism is associated with experiencing pleasure in relation to a stranger's misfortune, for example searching for videos of those experiencing pain (Porter et al., 2014), displaying positive emotions in response to sad images (Ali, Amorim, \& Chamorro-Premuzic, 2009), and correlated with experiencing schadenfreude in relation to a co-worker's misfortune (James, et al., 2014). However, these studies, whilst informative, do not establish the relationship between Machiavellianism and 
schadenfreude in close personal relationships, and in particular do not provide information on female friendships, which have been shown to be influenced by Machiavellianism. (e.g., Abell, Brewer, Qualter, \& Austin, 2016).

Indeed, women's friendships may be a unique context in which schadenfreude is experienced by individuals higher on Machiavellianism, envy, and competition. Women have a strong interest in gathering information about other women (McAndrew, 2014) and although women's friendships are often characterized by positive attributes such as intimacy, emotional sharing, and closeness (Caldwell \& Peplau, 1982; Vigil, 2007), women engage in more subtle manipulation such as relational aggression (Wilson, Near, \& Miller, 1996) with name-calling, gossiping, derogating reputation, ostracism, and ridicule among the most frequent forms of female-female aggression (Laidler \& Hunt, 2001; McAndrew, 2014; Miller-Ott \& Kelly, 2013a; Owens, Shute, \& Slee, 2000). Women may also be less supportive and more critical of each other than men in other contexts such as the workplace (Chesler, 2001; Mavin, Williams, \& Grandy, 2014). Relational aggression directed at other women may reflect conflict over romantic partners or same-sex friends (Bleske-Rechek \& Lighthall, 2010; Miller-Ott \& Kelly, 2013a) and is often viewed as a typical or acceptable part of women's communication (Miller-Ott \& Kelly, 2013b). Indeed, female competition may prompt women to seek alternative relationships such as friendships with homosexual men who may be perceived as more trustworthy than their same-sex heterosexual friends (Russell, Ta, Lewis, Babcock, \& Ickes, 2017). Negative behavior is more frequent among women higher on Machiavellianism, who report their same-sex friendships to provide lower levels of intimacy and companionship, and engage in emotional manipulation and online relational aggression towards their same-sex friends (Abell et al., 2016; Abell \& Brewer, 2014). 
Schadenfreude is experienced at a psychological distance rather than directly causing the misfortune (Porter, Bhanwer, Woodworth, \& Black, 2014) and thus may be more prevalent amongst those displaying the emotional detachment that characterizes Machiavellianism (Christie \& Geis, 1970). Individuals higher on Machiavellianism have a broad negative view of others (Black, Woodworth, \& Porter, 2014; Christie \& Geis, 1970) and perceive others to be controlling, hostile, punitive, and demanding (Sherry, Hewitt, Besser, Flett, \& Klein, 2006). In summary, previous research has demonstrated that Machiavellianism, envy, and competition predict feelings of schadenfreude in general relationships. Furthermore, Machiavellianism has been shown to be related to envy and competition (Jonason, Wee, \& Li, 2015; Jonason, Zeigler-Hill, \& Okan, 2017; Veselka, Giammarco, \& Vernon, 2014). The present study adds to the existing literature by investigating Machiavellianism, envy, competition, and the experience of schadenfreude in women's same-sex friendships. We predict women higher on Machiavellianism, envy, and competition will report higher levels of schadenfreude in each context (i.e., academic ability, romantic relationship, and physical appearance) investigated.

\section{Method}

\section{Participants}

Women $(N=133)$ aged $18-30$ years $(M=21.65, S D=3.40)$ with an average friendship length of 7.5 years ( $S D=5$ years, 18 missing data) were recruited via online research websites (e.g., www.onlinepsychresearch.co.uk) and social networking sites (e.g., Twitter).

\section{Materials and Procedure}

Women responded to three vignettes measuring schadenfreude with a same-sex friend and completed the Mach IV (Christie \& Geis, 1970), Dispositional Envy Scale (Smith, 
Parrott, Diener, Hoyle, \& Kim, 1999), and Interpersonal Competition Index (Singleton \& Vacca, 2007). Mean scores were used in subsequent analyses.

Schadenfreude. This was measured with three vignettes following the method utilized by James, et al. (2014). Scenario one was specifically adapted from the James et al. (2014) paper with the remaining two scenarios devised by the researchers. The three scenarios were devised based on experiences that are likely to occur in female friendships which may evoke feelings of schadenfreude. The vignettes reflect three different contexts: academic/work success, romantic relationship success, and physical appearance.

Scenario one:

"Your friend is always gloating about her abilities. You find out they recently got a bad grade/performance review."

Scenario two:

"Your friend constantly talks about how happy she is with her romantic partner and how perfect he/she is. Their partner then ends their relationship."

Scenario three:

"Your friend always talks about how good she looks and how other people compliment her on her appearance. She then gets what turns out to be a very bad haircut. Other people notice and talk about this."

After reading each of the three scenarios participants rated on a seven point scale $(1=$ strongly disagree to 7 = strongly agree) the extent to which they felt amused, satisfied, pleased, and sympathetic. Sympathetic scores were reverse coded. Responses to each scenario revealed good internal consistency (scenario 1: $\alpha=.82, M=10.83, S D=5.51$; scenario 2: $\alpha=.82, M=6.62, S D=3.89$; scenario $3: \alpha=.87, M=10.38, S D=4.99$ ); therefore scores were averaged to form a schadenfreude index for each scenario. 
Machiavellianism. The Mach IV (Christie \& Geis, 1970) contains 20 items rated on a seven point scale $(1=$ strongly disagree to 7 = strongly agree $)$ with higher scores indicating higher levels of Machiavellianism. Example items include "Anyone who completely trusts anyone else is asking for trouble" and "Never tell anyone the real reason you did something unless it is useful to do so". The scale had good internal reliability $(\alpha=.74, M=70.12, S D=$ 13.10).

Envy. The Dispositional Envy Scale (Smith, et al., 1999) contains eight items rated on a five point scale $(1=$ strongly disagree to $5=$ strongly agree $)$ with higher scores indicating higher levels of envy. Items were adapted to reflect feelings of envy towards a friend, for example "Feelings of envy about my friend constantly torment me" and "I am troubled by feelings of inadequacy compared to my friend". The scale had good internal reliability $(\alpha=.83, M=12.37, S D=4.78)$.

Competition. The Interpersonal Competition Index (Singleton \& Vacca, 2007) comprises of seven items assessing general competition (three items) and competition within specific domains (four items). Participants responded on a seven point Likert scale $(1=$ strongly disagree to $5=$ strongly agree) to statements such as "There is a feeling of competition between me and my friend". Three of the statements were adapted as the Singleton and Vacca (2007) questionnaire was intended for college students and concentrated on school grades. For example, "I don't like my friend to get better grades than I do" was adapted to "I don't like my friend to achieve more than I do". Analysis revealed good reliability $(\alpha=.80, M=11.69, S D=5.29)$

\section{Results}

\section{Correlations}

Correlations between Machiavellianism, envy, competition, and the schadenfreude scenarios showed that envy and competition were significantly positively correlated with 
schadenfreude in scenario 1 (academic abilities) and Machiavellianism, envy, and competition were each significantly positively associated with scenario 2 (romantic relationship) and scenario 3 (physical appearance). See Table 1 for correlations.

\section{Regressions}

In order to test for mediation, bootstrapped regressions were first conducted to investigate whether Machiavellianism predicted envy and competition. However, analysis revealed that Machiavellianism did not predict envy $(\beta=.07, t=.70, p=.419)$ or competition $(\beta=.05, t=.53, p=.291)$. Therefore, simultaneous regressions were conducted to investigate whether Machiavellianism, competition, and envy predicted schadenfreude.

Separate bootstrapped regressions analyses (controlling for age and friendship length) were conducted to investigate whether Machiavellianism, envy, and competition in women predicted schadenfreude in each of the three scenarios. The models were significant in predicting experience of schadenfreude in scenario one $(F(5,109)=11.24, p<.001)$, scenario two $(F(5,109)=7.34, p<.001)$, and scenario three $(F(5,109)=8.78, p<.001)$ .001). Machiavellianism alone (after controlling for age and friendship length) did not significant predict schadenfreude in scenario one i.e., academic abilities $(\beta=.08, t=.99, p=$ $.357)$, but envy $(\beta=.17, t=2.00, p=.04)$ and competition $(\beta=.49, t=5.56, p=.001)$ individually predicted feelings of schadenfreude in this scenario. In scenario two (romantic relationship), Machiavellianism $(\beta=.29, t=3.42, p=.007)$, envy $(\beta=.122 t=2.44, p=$ $.005)$, and competition $\beta=.26, t=2.76, p=.006)$ individually predicted schadenfreude. Finally, in scenario three (physical appearance), Machiavellianism $(\beta=.24, t=2.81, p=$ $.014)$ and competition $(\beta=.40, t=4.40, p=.001)$ individually predicted feelings of schadenfreude to a same-sex friend but envy was not significant in predicting schadenfreude $(\beta=.11, t=1.22, p=.229)$. 


\section{Discussion}

The present study demonstrated that women higher on Machiavellianism experienced feelings of pleasure when their same-sex friend experienced misfortune in romantic relationships and physical appearance. This study expands on Porter et al.'s, (2014) research by focusing on schadenfreude in female same-sex friendships and also highlights the role of envy and competition in experiencing schadenfreude. Envy predicted experiencing schadenfreude in relation to academic/work ability and romantic relationships whilst competition predicted experiencing schadenfreude in all three scenarios. The findings are consistent with previous research documenting the relationship between Machiavellianism and schadenfreude in response to a co-worker's misfortune (James, et al., 2014) and research highlighting the emotional manipulation and relational aggression which characterizes the relationships of Machiavellian women (Abell \& Brewer, 2014; Abell, et al. 2016).

Women higher on Machiavellianism experienced pleasure at the friend's misfortune in two domains; romantic relationships and physical attractiveness, which may reflect greater competition for partners (or willingness to complete with close same-sex friends for partners) amongst women with high levels of Machiavellianism (Brewer \& Abell, 2015). Indeed, a same-sex friend experiencing misfortune in these two domains may create sexual opportunities for these women. Previous research demonstrates that women may direct a range of behaviors (e.g., derogation) at perceived rivals which may serve to intimidate rivals, reduce their attractiveness, and hinder success (Fisher, 2004; Fisher \& Cox, 2009). Whilst effective, this behavior may lead to retaliation or a damaged social reputation suggesting that such competitive behavior should be employed on a limited basis or only under certain circumstances (e.g., when retaliation is unlikely). Schadenfreude may signal that the threat posed by rivals is lowered, for example, they are less likely to attract a desirable mate. Future 
studies may consider whether experiencing schadenfreude then facilitates future sexual behavior.

Machiavellianism did not predict envy or competition thus mediation or moderation analysis could not be conducted. This is inconsistent with previous research showing the relationship between Machiavellianism and envy and competition. Envy is characterized as '...desiring the advantage or wishes that the envied person lacks' (Lange \& Crusius, 2015, p.284). This may suggest that the women in this study did not either view their friend as having advantages or were not envious of any advantages they may have had. Engaging in envy is not an advantageous strategy to adopt as envy may act as a distractor from their longterm goals. These women may not feel envious of others as they carefully select people to be in their social circle who have characteristics that make them more vulnerable to manipulation and exploitation. Indeed, research has demonstrated those high on Machiavellianism select friends who are kind (Jonason \& Schmitt, 2012) and place little importance on friendship quality, companionship, emotional security, and intimacy (Abell et al.; 2016; Lyons \& Aitken, 2010). Alternatively, the qualities displayed by a friend (e.g., professional success) may be viewed as an opportunity for exploitation (e.g., greater financial resources or contacts) rather than as a source of discontent.

Similarly, Machiavellianism did not predict competition. This may suggest that the women in this study did not view their friend as having competitive advantages that they saw as a threat. Women with higher Machiavellianism scores may select friends who they do not view as competitive as extra energy/resources would be required to compete with them which could detract focus from their primary goals. Instead, women higher on Machiavellianism may select friends who are not competitive and easier to exploit. Indeed, Machiavellianism is associated with seeking closeness in order to manipulate (Ináncsi, Láng, \& Bereczkei, 2015) and a person high in competition may become a barrier to this form of manipulation. Future 
research should adopt a dyadic approach and investigate characteristics of both individuals and how each views the characteristics of their friend. This may help to provide a clearer picture on the relationship between Machiavellianism and competition (and potentially schadenfreude) in friendships.

However, although Machiavellianism did not predict envy and competition, envy (in scenario one and two) and competition (all three scenarios) did predict schadenfreude. Given that women report their same-sex friends compete with them for potential romantic partners (Bleske \& Buss, 2000), women who perceived their friendship as more competitive or reported feeling envious of their friend may view them as being less of a threat when experiencing misfortune. Schadenfreude may signal that the threat posed by rivals is lowered, they are less likely to attract a desirable mate, and (for competition) less likely to increase in status (i.e., through a job promotion) in the workplace. Experiencing schadenfreude could increase self-esteem through engaging in social comparison and viewing oneself as higher on the social/work hierarchy. This could then act as a motivator to seek out opportunities and increase own status and resources. Indeed, envy, competition, and schadenfreude could be related to the 'Queen Bee' phenomenon in the workplace and leadership (Derks, Van Laar, \& Ellemers, 2016), although research is needed to investigate this possible relationship.

\section{Limitations and Future Research}

The present study employed hypothetical scenarios, whilst consistent with previous schadenfreude research (e.g. James et al., 2014), additional research investigating responses to actual misfortune is recommended. These studies should establish the manner in which Machiavellianism influences emotional responses to misfortune of varying severity and scope (such as poor health), behavioral responses to this misfortune (e.g., providing instrumental or emotional support), and motivation for such behavior (e.g., to reduce distress or gain access to information). As cynicism and distrust are important features of Machiavellianism, future 
research may also consider the manner in which those with high levels of Machiavellianism expect others to respond (both publicly and privately) when they themselves experience misfortune. Importantly, this study found that Machiavellianism did not predict envy in this sample of women. Recent research has shown that envy can be categorized into benign and malicious envy (Lange \& Crusius, 2015), with benign envy being associated with the motivation to move upwards and malicious envy associated with pulling others who are superior down. Thus future research should investigate whether Machiavellianism predicts either of these components of envy and schadenfreude, with the prediction that Machiavellianism would be associated with benign envy which may then relate to schadenfreude.

Furthermore, this study recruited participants through two different online platforms. Previous research has shown that there are differences in responses when conducting online and offline research (Zhang, Kuckinke, Woud, Velten, \& Margraf, 2017) and such differences may also apply to the use of different online platforms. Therefore, future research should account for the use of different online platforms. Lastly, this study only focused on a specific gender, age group, and relationship type. Future research should be conducted investigating different age groups, different relationships, and investigate possible differences in men and women's experiences of schadenfreude.

To conclude, the present study demonstrates that women with high levels of Machiavellianism were more likely to experience pleasure in response to a same-sex friend's misfortune in romantic relationships and physical appearance. Findings are consistent with previous research, in particular those documenting pleasure in response to sad images and a colleague's misfortune. However, Machiavellianism did not predict envy or competition although these constructs themselves did predict schadenfreude. Future research should focus on individual components of envy and the attributes of the envied person/victim of 
schadenfreude to provide a more detailed picture of the relationship between Machiavellianism and experiencing schadenfreude in personal relationships. 
Table 1: Correlations for Machiavellianism, Envy, Competition, and each Schadenfreude Scenario

\begin{tabular}{|c|c|c|c|c|c|c|c|c|}
\hline & Age & $\begin{array}{l}\text { Friendship } \\
\text { Length }\end{array}$ & Mach & Envy & Competition & $\begin{array}{l}\text { Scenario } \\
1\end{array}$ & $\begin{array}{l}\text { Scenario } \\
2\end{array}$ & $\begin{array}{l}\text { Scenario } \\
3\end{array}$ \\
\hline Age & & .10 & -.17 & -.13 & $-.24 * *$ & -.05 & -.04 & -.11 \\
\hline $\begin{array}{l}\text { Friendship } \\
\text { length }\end{array}$ & & & -.15 & -.02 & .18 & .16 & .06 & .11 \\
\hline Mach & & & & .08 & .09 & .14 & $.30 * *$ & $.27 * *$ \\
\hline Envy & & & & & $.35 * *$ & $.33 * *$ & $.29 * *$ & $.30 * *$ \\
\hline Competition & & & & & & $.50 * *$ & $.36^{* *}$ & $.49 * *$ \\
\hline Scenario 1 & & & & & & & $.55^{* *}$ & $.47 * *$ \\
\hline Scenario 2 & & & & & & & & $.54 * *$ \\
\hline Scenario 3 & & & & & & & & \\
\hline
\end{tabular}

Notes: Mach= Machiavellianism, $* * p<.01$ 


\section{References}

Abell, L., \& Brewer, G. (2014). Machiavellianism, self-monitoring, self-promotion and relational aggression on Facebook. Computers in Human Behavior, 36, 258-262.

Abell, L., Brewer, G., Qualter, P., \& Austin, E. (2016). Machiavellianism, emotional manipulation, and friendship functions in women's friendships. Personality and Individual Differences, 88, 108-113.

Abell, L., Lyons, M., \& Brewer, G. (2014). The relationship between parental bonding, Machiavellianism and adult friendship quality. Individual Differences Research, 12, 191-197.

Ali, F., Sousa Amorim, I., \& Chamorro-Premuzic, T. (2009). Empathy deficits and trait emotional intelligence in psychopathy and Machiavellianism. Personality and Individual Differences, 47, 758-762.

Black, P. J., \& Woodworth, M., \& Porter, S. (2014). The Big Bad Wolf? The relation between the Dark Triad and the interpersonal assessment of vulnerability. Personality and Individual Differences, 67, 52-56.

Bleske, A. L., \& Buss, D. M. (2000). Can men and women be just friends? Personal Relationships, 21, 131-151.

Bleske-Rechek, A., \& Lighthall, M. (2010). Attractiveness and rivalry in women's friendships with women. Human Nature, 21, 82-97.

Boddy, C. R., Ladyshewsky, R. K., \& Galvin, P. (2010). The influence of corporate psychopaths on corporate social responsibility and organizational commitment to employees. Journal of Business Ethics, 97, 1-19.

Brewer, G., \& Abell, L. (2015). Machiavellianism in long-term relationships: Competition, mate retention and sexual coercion. Scandinavian Journal of Psychology, 56, 357362. 
Caldwell, M. A., \& Peplau, L. A. (1982). Sex differences in same-sex friendship. Sex Roles, $8,721-732$.

Chesler, P. (2001). Women's Inhumanity to Woman. New York: Thunder's Mouth Press, Nation's Books.

Christie, R., \& Geis, F. L. (1970). Studies in Machiavellianism. London: Academic Press.

Derks, B., Van Laar, C., \& Ellemers, N. (2016). The queen bee phenomenon: Why women leaders distance themselves from junior women. The Leadership Quarterly, 27, 456469.

Fisher, M. L. (2004). Female intrasexual competition decreases female facial attractiveness. Proceedings of the Royal Society B: Biological Sciences, 271, S283-S285.

Fisher, M. L., \& Cox, A. (2009). The influence of female attractiveness on competitor derogation. Evolutionary Psychology, 7, 141-155.

Inancsi, T., Lang, A. G., \& Bereczkei, T. (2015). Machiavellianism and adult attachment in general interpersonal and close relationships. Europe's Journal of Psychology, 11, 139-154.

James, S., Kavanagh, P. S., Jonason, P. K., Chonody, J. M., \& Scrutton, H. E. (2014). The Dark Triad, schadenfreude, and sensational interests: Dark personalities, dark emotions, and dark behaviors. Personality and Individual Differences, 68, 211-216.

Jonason, P. K., \& Schmitt, D. P. (2012). What have you done for me lately? Friendshipselection in the shadow of the Dark Triad traits. Evolutionary Psychology, 10, 400421.

Jonason, P. K., \& Webster, G. D. (2012). A protean approach to social influence: Dark Triad personalities and social influence tactics. Personality and Individual Differences, 52, $521-526$. 
Jonason, P. K., Wee, S., \& Li, N. P. (2015). Competition, autonomy, and prestige: Mechanisms through which the Dark Triad predict job satisfaction. Personality and Individual Differences, 72, 112-116.

Jonason, P. K., Zeigler-Hill, V., \& Okan, C. (2017). Good V. evil: Predicting sinning with dark personality traits and moral foundations. Personality and Individual Differences, 104, 180-185.

Jones, D. N., \& Paulhus, D. L. (2011). The role of impulsivity in the Dark Triad of personality. Personality and Individual Differences, 51, 679-682.

Laidler, K. J., \& Hunt, G. (2001). Accomplishing femininity among the girls in the gang. British Journal of Criminology, 41, 656-678.

Lange, J., \& Crusius, J. (2015). Dispositional envy revisited: Unraveling the motivational dynamics of benign and malicious envy. Personality and Social Psychology Bulletin, 41, 284-294.

Lyons, M., \& Aitken, S. (2010). Machiavellian friends? The role of Machiavellianism in friendship formation and maintenance. Journal of Social, Evolutionary and Cultural Psychology, 4, 194-202.

Mavin, S., Williams, J., \& Grandy, G. (2014). Negative Intra-Gender Relations between Women: Friendship, Competition and Female Misogyny. In The Oxford Handbook of Gender in Organizations. Oxford: Oxford University Press. pp. 223-248.

McAndrew, F. T. (2014). The "sword of a woman": Gossip and female aggression. Aggression and Violent Behavior, 19, 196-199.

Miller-Ott, A. E., \& Kelly, L. (2013a). Communication of female relational aggression in the college environment. Qualitative Research Reports in Communication, 14, 19-27. 
Miller-Ott, A. E., \& Kelly, L. (2013b). Mean girls in college: An analysis of how college women communicatively construct and account for relational aggression. Women's Studies in Communication, 36, 330-347.

Owens, L., Shute, R., \& Slee, P. (2000). “Guess what I just heard!”: Indirect aggression among teenage girls in Australia. Aggressive Behavior, 26, 67-83.

Porter, S., Bhanwer, A., Woodworth, M., \& Black, P. J. (2014). Soldiers of misfortune: An examination of the Dark Triad and the experience of schadenfreude. Personality and Individual Differences, 67, 64-68.

Rosenberg, M. (1965). Society and the Adolescent Self-Image. Princeton, NJ: Princeton University Press.

Russell, E. M., Ta, V. P., Lewis, D. M. G., Babcock, M. J., \& Ickes, W. (2017). Why (and when) straight women trust gay men: Ulterior mating motives and female competition. Archives of Sexual Behavior, 46, 763-773.

Sherry, S. B., Hewitt, P. L., Besser, A., Flett, G. C., \& Klein, C. (2006). Machiavellianism, trait perfectionism, and perfectionistic self-presentation. Personality and Individual Differences, 40, 829-839.

Singelton Jr, R. A., \& Vacca, J. (2007). Interpersonal competition in friendships. Sex Roles, 57, 617-627.

Smith, R. H., Parrott, W. G., Diener, E. F., Hoyle, R. H., \& Kim, S. H. (1999). Dispositional Envy Scale. Personality and Social Psychology Bulletin, 25, 1070-1020.

Takahashi, H., Kato, M., Matsuura, M., Mobbs, D., Sahura, T., \& Okobu, Y. (2009). When your gain is my pain and your pain is my gain: Neural correlates of envy and schadenfreude. Science, 323, 937-939. 
Van Dijk, W. W., Ouwerkerk, J. W., Goslinga, S., Nieweg, M., \& Gallucci, M. (2006). When people fall from grace: Reconsidering the role of envy in schadenfreude. Emotion, 6, 156-160.

Van Dijk, W. W., van Koningsbruggen, G. M., Ouwerkerk, J. W., \& Wesseling, Y. M. (2011). Self-esteem, self-affirmation, and schadenfreude. Emotion, 11, 1445-1449.

Veselka, L., Giammarco, E. A., \& Vernon. (2014). The dark triad and the seven deadly sins. Personality and Individual Differences, 67, 75-80.

Zhang, X., Kuckinke, L., Woud, M. L., Velten, J., \& Margraf, J. (2017). Survey method matters: Online/offline questionnaires and face-to-face or telephone interviews differ. Computers in Human Behavior, 71, 172-180. 